\title{
Modeling and calculation of hydromechanical systems dynamics based on the volume rigidity theory
}

\author{
Alexander T. Rybak $^{1,{ }^{*}}$ Mikhail P. Shishkarev ${ }^{1}$, Alexander A. Demyanov ${ }^{2}$, Viktor P. Zharov ${ }^{1}$ \\ ${ }^{1}$ Don State Technical University, 344000 Rostov-on-Don, Russian Federation \\ ${ }^{2}$ Rostov State Transport University, 344038 Rostov-on-Don, Russian Federation
}

\begin{abstract}
A method for modeling hydraulic systems of hydromechanical devices based on the application of the volume rigidity theory - the property of the hydraulic system to keep its volume unchanged when the pressure of the working medium changes is proposed. The main analytical dependencies intended for modeling the hydraulic system are presented. An example of simulation and calculation of a hydromechanical shock absorber system which confirms the correctness and convenience of using the volume rigidity theory in modeling hydromechanical drive systems of complex machines is presented. The results of the numerical experiment make it possible to evaluate the functioning quality of the drive system under investigation to reveal the effect of the main design and system functional parameters on its operation. The graphs of the change in the main functional parameters of the shock absorber under investigation in real time are given, which make it possible to visually evaluate the results of a numerical experiment and draw conclusions about the need for modernization.
\end{abstract}

\section{Introduction}

Modeling and designing calculation of hydraulic systems in practice is a very difficult task due to the need to adequately describe the large number of nonlinear processes arising in such systems. Especially a lot of nonlinear problems arise when modeling and calculating the hydraulic systems of various devices. The most convenient and rational is the simulation of hydraulic systems using the foundations of the volume rigidity theory [1-8]. The property to resist changes in the internal volume of the system under the changing pressure influence is the volume rigidity of the hydraulic system.

\section{Fundamentals of the theory of volume rigidity}

The essence of the volume rigidity theory using in modeling consists in the assertion that the pressure at any $1^{\text {st }}$ point of the $d p_{i}$ hydraulic system can be determined by equation (1).

\footnotetext{
*Corresponding author:2130373@mail.ru
} 


$$
d p_{i}=C_{p r i} \cdot\left(\sum Q_{v h_{i}}-\sum Q_{v y h_{i}}\right) \cdot d t
$$

where $\sum Q_{v h_{i}}$ and $\sum Q_{v y h_{i}}$ - the sums of all incoming and outgoing instantaneous flow rates of the hydraulic fluid of the volume of the hydraulic system in time $d t ; C_{p r i}$ - the reduced coefficient of volume rigidity of the $i$-th hydraulic system volume under consideration.

Thus the main task, when modeling the hydraulic system, is to determine the reduced coefficient of volume rigidity of the system various elements, which is equal to the increase in pressure, which is due to the addition of an additional volume of the working fluid to this element volume.

The previously obtained formulas for determining the reduced coefficients of volume rigidity of hydraulic systems some elements [9-11] are summarized in Table 1.

Table 1. The resulted factors of volume rigidity of hydraulic systems various elements.

\begin{tabular}{|c|c|c|}
\hline № & System element & The reduced coefficient of volume rigidity \\
\hline 1 & Hydraulic line section & $C_{l}=\frac{E_{\text {oil }}}{V_{t r}\left(1+\frac{d}{\delta} \frac{E_{\text {oil }}}{E_{s t}}\right)}, \quad C_{l}=\frac{4}{\pi \cdot d_{0}^{2} \cdot l_{0}} \times \frac{E_{\text {oil }}}{1+\frac{d_{0}}{\delta} \frac{E_{o i l}}{E_{s t}}}$ \\
\hline 2 & Cylinder piston side & $C_{c . p}=\frac{4 E_{o i l}}{\pi \cdot d_{c}^{2} \cdot x \cdot\left(1+\frac{d_{c}}{\delta} \frac{E_{o i l}}{E_{s t}}\right)+4 V_{c . v r}}$ \\
\hline 3 & Cylinder end & $C_{\text {sht }}=\frac{4 E_{\text {oil }}}{\pi \cdot(L-x) \cdot\left[\left(d_{c}^{2}-d_{s h t}^{2}\right)+\frac{d_{c}^{3}}{\delta_{c}} \frac{E_{o i l}}{E_{s t}}\right]+4 V_{\text {sht.vr }}}$ \\
\hline 4 & $\begin{array}{l}\text { Working cavity of the } \\
\text { plunger hydraulic } \\
\text { cylinder }\end{array}$ & $C_{c . p l}=\frac{4 E_{o i l}}{\pi \cdot d_{c}^{2} \cdot \frac{d_{c}}{\delta_{c}} \frac{E_{o i l}}{E_{s t}}-F_{p l}(L-x)}$ \\
\hline 5 & $\begin{array}{l}\text { Working cavity of the } \\
\text { hydro-pneumatic } \\
\text { accumulator }\end{array}$ & $C_{\text {Voil }}=\frac{E_{\text {oil }}}{V_{0}\left[1-\left(\frac{p_{0}}{p}\right)^{\frac{1}{k}}+\frac{E_{\text {oil }}}{k p}\left(\frac{p_{0}}{p}\right)^{\frac{1}{k}}\right]}$ \\
\hline 6 & $\begin{array}{c}\text { Piston hydraulic } \\
\text { pneumatic storage } \\
\text { housing }\end{array}$ & $C_{V s t}=\frac{E_{s t}}{V_{0}\left(\frac{2}{\bar{d}-1}+\frac{1}{\bar{d}^{2}-1}\right)}$ \\
\hline
\end{tabular}

Table 1 assumes the following notation:

$V_{t r}$ - internal volume of the conduit section in question; $d$ and $\delta$ - diameter of the conduit and its wall thickness; $E_{s t}$ - elasticity modulus of the wall material; $E_{\text {oil }}$ - elasticity modulus of power fluid; $d_{c}-$ inner diameter of cylinder liner; $\delta_{c}$ - hydraulic cylinder wall thickness; $x$ - piston stroke of the hydraulic cylinder from its lower dead center; $V_{c . v r}-$ volume of harmful space in the piston cavity of the hydraulic cylinder; $L-$ full stroke of the piston (plunger) of the hydraulic cylinder; $d_{s h t}$ - hydraulic cylinder rod diameter; $V_{\text {sht.vr }}$ - harmful space volume of the hydraulic cylinder rod cavity; $F_{p l}$ - cross-sectional area of hydraulic cylinder ram; $V_{p l . v r}$ - harmful space volume of the plunger hydraulic cylinder power cavity; $C_{\text {Voil }}$ - the reduced volume rigidity coefficient of the hydropneumatic accumulator gas-liquid chamber; $C_{V_{s t}}$ - the reduced volume rigidity coefficient of the body wall of a hydropneumatic accumulator; $p_{0}$ - gas pressure under charging a hydropneumatic 
accumulator; $p$ - the pressure current value of the hydroneumatic accumulator power fluid in the working cavity; $k$-adiabatic exponent; $\bar{d}$ - the outer diameter of the battery case wall is related to its internal diameter; $V_{0}-$ the full volume of the hydropneumatic accumulator working cavity (without taking into account the volume of the separator).

The volume rigidity reduced coefficients definition of high-pressure hoses is a particular difficulty, the elastic properties of which do not lend themselves to a simple analytic description [11-13].

If several different hydraulic elements are included at some point in the system, each of which has its own volume rigidity, then assuming that the pressure change at a given point is instantaneously transmitted over the entire volume under consideration, the volume rigidity reduced coefficient of elements such a system can be determined by formula (2).

$$
C_{p r}=\frac{\prod_{i=1}^{n} C_{i}}{\sum_{i=1}^{n}\left(\frac{1}{C_{i}} \prod_{i=1}^{n} C_{i}\right)}
$$

where $C_{p r}$ - the hydraulic system volume rigidity reduced coefficient consisting of $n$ cooperating elements; $C_{i}$ - the volume rigidity reduced coefficient of the $i$ element of the system.

The flow rate values of the power fluid, necessary for calculating the increment of pressures, are determined by the formula (3).

$$
Q_{i}=\mu_{i} \cdot S_{i} \cdot \sqrt{\frac{2}{\rho} \cdot\left|p_{i}-p_{i+1}\right|} \cdot \operatorname{sign}\left(p_{i}-p_{i+1}\right),
$$

where $p_{i}$ - the pressure value at the input of the $i$-th hydraulic resistance; $p_{(i+1)}$ - pressure output; $S_{i}$ - cross-sectional area of resistance; $\rho$ - power fluid density; $\mu_{i}$ - resistance flow coefficient.

\section{Modeling of hydromechanical shock absorber system}

Consider the hydraulic systems modeling and calculation process of using the example of a hydropneumatic shock absorber hydromechanical system.

The shock absorber circuit is shown in Figure 1 . It includes a cylindrical body 1 divided by a piston 2 into a main chamber 3 and a return chamber 4 filled with a liquid. Hollow rod 5, in turn, has two independent chambers: cylindrical 6 and annular 7, filled with compressed gas and having movable sealing elements in the form of washer 8 and rings 9 . The chambers 6 and 7 are connected to each other by apertures in the upper part of the rod. In this case, the annular chamber 7 is hydraulically connected to the main chamber 3 by means of throttling holes 11 , and the cylindrical chamber 6 is connected to the chamber 3 via the pressure valve 10 .

The shock absorber works as follows. When a certain force is exerted on the rod 5, it, together with the piston 2, moves to the top. In this case, the liquid in the chamber 3 is forced out through the throttling holes 11 into the annular chamber 7, and through the holes 12 into the return chamber 4 . Due to the throttling of the liquid in the holes 11 , the pressure in the chamber 3 increases, which reduces the speed of the piston, in addition, when the chambers 6 and 7 are filled with liquid, the gas under the separators 8 and 9 is compressed, which in turn slows the piston 2 movement. If the force $F$ is significant and the speed of 
movement of the piston 2 is large, the pressure valve 10 opens and the damping occurs mainly due to gas compression in the chambers 6 and 7 .

The mathematical description of the shock absorber dynamic behavior in accordance with the volume rigidity theory will look like:

$$
\begin{gathered}
d p_{1}=C_{p r 1} \cdot\left(v_{p} \cdot \mathrm{S}_{p}-Q_{(1-7)}-Q_{11}-Q_{12}\right) \cdot d t ; \\
d p_{2}=C_{p r 2} \cdot\left(Q_{12}-v_{p} \cdot S_{\text {ring.koh }}\right) \cdot d t ; \\
d p_{3}=C_{p r 3} \cdot\left(Q_{11}-v_{\text {ring } 9} \cdot S_{\text {ring } 9}-Q_{(3-4)}\right) \cdot d t ; \\
d p_{4}=C_{p r 4} \cdot\left(Q_{k l 10}+Q_{(3-4)}-v_{\text {shim } 8} \cdot S_{\text {shim } 8}\right) \cdot d t ; \\
p_{5}=p_{05} \cdot\left(\frac{V_{05}}{V_{05}-S_{\text {ring } 9} \cdot x_{\text {ring } 9}}\right)^{k} ; \\
p_{6}=p_{06} \cdot\left(\frac{V_{06}}{V_{06}-S_{\text {shim } 8} \cdot x_{\text {shim } 8}}\right)^{k} ; \\
d_{p 7}=C_{p r 7} \cdot\left(Q_{(1-7)}-Q_{r l 10}\right) \cdot d t .
\end{gathered}
$$

where $p_{1} \ldots p_{7}-$ pressure at the corresponding points of the system; $v_{p}, v_{\text {ring } 9}$ and $v_{\text {shim } 8}$ - speed of piston displacement, ring 9 and washer 8 , respectively; $S_{p}, S_{\text {ring.koh }}, S_{\text {ring } 9}$ and $S_{\text {shim } 8}$ - the piston area, the return chamber ring, the ring 9 and the washer 8 , respectively; $Q_{(1-7)}$ and $Q_{(3-4)}$ - the power fluid flow between the system corresponding points; $Q_{11}, Q_{12}$ and $Q_{k l 10}$ - the power fluid flow through the chokes 11, 12 and through the valve 10, respectively; $C_{p r 1} \ldots C_{p r 4}$ and $C_{p r 7}$ - the volume rigidity reduced coefficients at the system corresponding points; $t$ - time; $p_{05}$ and $p_{06}$ - precharge gas pressure in the respective chambers; $V_{05}$ and $V_{06}$ - initial volumes of gas in the respective chambers; $x_{\text {ring } 9}$ and $x_{\text {shim } 8}-$ the movement of the ring 9 and the washer 8 from the initial state, respectively; $k$ - the adiabatic index of the gas.

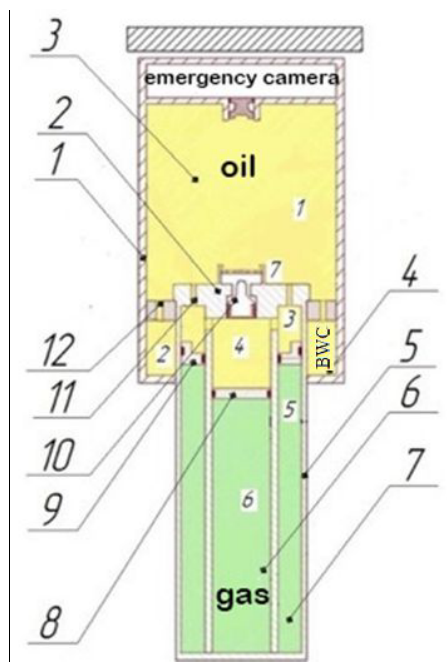

Fig. 1. The calculation scheme of the hydropneumatic shock absorber

The equation of the piston motion together with the stem 5 , the rings 9 , the washers 8 and the valve plug 10 are:

$$
d v_{p}=\frac{1}{m_{p r \cdot p}}\left(F+S_{\text {ring.koh }} \cdot p_{2}-S_{p} \cdot p_{1}-F_{t r . p}\right) ;
$$




$$
\begin{aligned}
& d v_{\text {ring } 9}=\frac{1}{m_{\text {ring } 9}}\left(S_{\text {ring } 9} \cdot\left(p_{3}-p_{5}\right)-F_{t r . k}\right) ; \\
& d v_{k l 10}=\frac{1}{m_{k l 10}}\left[S_{k l 10} \cdot\left(p_{7}-p_{4}\right)-c_{p r}\left(x_{0 k l}+x_{k l}\right)\right] ; \\
& d v_{\text {shim } 8}=\frac{1}{m_{\text {shim } 8}}\left[S_{\text {shim } 8} \cdot\left(p_{4}-p_{6}\right)-F_{t r . s h}\right],
\end{aligned}
$$

where $F$ - force applied to the stock; $F_{t r . p}$ - frictional force due to rod movement; $m_{p r . p m}-$ reduced mass of elements moved when the piston moves; $F_{t r . k}-$ the frictional force arising when the ring 9 is moved; $m_{\text {ring } 9 m}$ - mass of ring $9 ; F_{t r . s h}-$ the frictional force that occurs when the washer 8 is moved; $m_{\text {shim } 8}$ - washer mass $8 ; S_{k 110}$ - valve opening area $10 ; m_{k l 10}-$ valve gate weight $10 ; c_{p r}$ - spring tightness of the valve shutter; $x_{0 k l}$ and $x_{k l}$ - the initial compression of the valve spring and the valve stroke, respectively.

\section{Calculation of the basic characteristics of the shock absorber}

To study the obtained mathematical model, using the Russian system of model-oriented design of automatic control systems (SimInTech) [14], a special program was developed that allowed analyzing the dynamics of the shock absorber operation.

Figures 2 and 3 show some results of a numerical experiment.

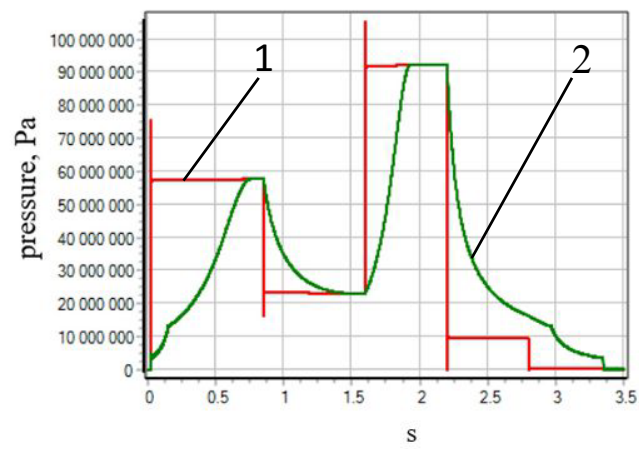

Fig. 2. Graph of changes in time of pressures $p_{1}$ - curve 1 and $p_{3}$ - curve 2

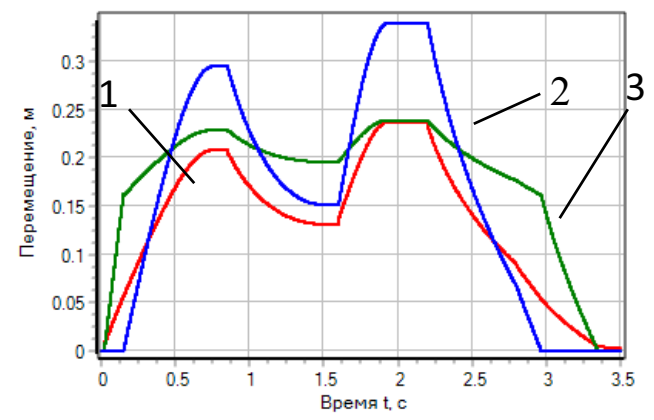

Fig. 3 Graph of change in time of movement: piston - curve 1, rings 9 - curve 2, washers 8 - curve 3

The calculations were made using the following algorithm. At the initial moment, the force on the rod is absent, and the pressure in all points of the hydraulic system, with the exception of the gas chambers, charged each with its pressure level, is equal to atmospheric 
pressure. At time $t_{1}=0.002 \mathrm{~s}$, the step load F1 $=5 \cdot 105 \mathrm{~N}$ is applied to the rod, which acts until the piston is completely stopped. Then the force acting on the rod at the time $t_{2}=0.85 \mathrm{~s}$ decreases to the value $F_{2}=2 \cdot 105 \mathrm{~N}$, which also acts until the piston is completely stopped. At the time $t_{3}=1.6 \mathrm{~s}$, the force on the rod again increases to the force $F_{3}=8 \cdot 105 \mathrm{~N}$, and at the time $t_{4}=2.2 \mathrm{~s}$, after the stem is completely stopped, the force decreases to the value $F_{4}=8 \cdot 104 \mathrm{~N}$ and after the rod is completely stopped at the time $t_{5}=2.8 \mathrm{~s}$, after the rod has completely stopped, $F_{5}=0$ is finally removed.

\section{Conclusions}

The numerical experiment has shown that a mathematical model constructed using the foundations of the volume rigidity theory makes it possible to produce theoretical studies of hydraulic systems with a high degree of accuracy and to observe their functioning in real time, revealing both the static and system dynamic properties.

In addition, the proposed mathematical model makes it possible to obtain the influence of various functional and design parameters on the quality of the shock absorber operation by performing a numerical experiment, and also to determine the rational parameters of the hydraulic system that ensure the best quality of the functioning dynamics.

\section{References}

1. A.T. Rybak, Teorija $i$ metodologija raschjota $i$ proektirovanija sistem privodov tehnologicheskih mashin i agregatov APK. Dokt. Diss. (Rostov-on-Don, 2011)

2. A.T. Rybak, Gidromekhanicheskie sistemy. Modelirovanie i raschet: monograph, (Gos. Tekh. Univ., Rostov-on-Don, 2008)

3. A.T. Rybak, I.V. Boguslavskiy, Vestnik of the DSTU, 276 (2010)

4. A.T. Rybak, Actual directions of scientific research of the XXI century: theory and practice, VGLTU, Voronezh, 9-3(20-2), 385 (2015)

5. A.T. Rybak, Proc. Int. Sc.-Techn. Sc.-Meth. Conf.: Hydrogasodynamics, hydraulic machines and hydropneumatic systems, 186 (2006)

6. A.T. Rybak, Vestnik of the DSTU, 2, 218 (2007)

7. A.T. Rybak, V.P. Zharov, A.V. Serdyukov, Russ. Eng. Res., 29(2), 194 (2009)

8. A.T. Rybak, A.R. Temirkanov, O.V. Lyakhnitskaya, Russ. Eng. Res., 38(3), 212 (2018)

9. V. P. Zharov, A.T. Rybak, S.A. Zatolokin, V.I. Mirnyj, Vestnik of the DSTU, 8, 4 (39), 177 (2008)

10. A.T. Rybak, V.P. Zharov, V.I. Mirnyj, S.A. Zatolokin, Proc. DTS-2007, 66 (2007)

11. A.T. Rybak, O.V. Lyakhnitskaya, Actual directions of scientific research of the XXI century: theory and practice, VGLTU, Voronezh, 271 (2015)

12. A.T. Rybak, O.V. Lyakhnitskaya, E.N. Shein, Proc. X Int. Sc. Meth. Symp., DSTU, 374 (2015)

13. A.T. Rybak, O.V. Lyakhnitskaya, MATEC Web Conf., 132, 01001 (2017)

14. B.A. Kartashov, Sreda dinamicheskogo modelirovaniya tekhnicheskikh sistem SimInTech: Praktikum po modelirovaniyu sistem avtomaticheskogo regulirovaniya (DMK Press, Moscow, 2017) 